\title{
The rate of force generation by the myocardium is not influenced by afterload
}

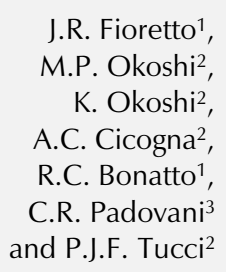

J.R. Fioretto ${ }^{1}$

M.P. Okoshi ${ }^{2}$,

K. Okoshi²,

A.C. Cicogna²,

R.C. Bonatto ${ }^{1}$,

C.R. Padovani ${ }^{3}$

and P.J.F. Tucci²

\author{
Departamentos de ${ }^{1}$ Pediatria and ${ }^{2}$ Clínica Médica, \\ Faculdade de Medicina de Botucatu, Universidade Estadual Paulista, \\ Botucatu, SP, Brasil \\ ${ }^{3}$ Departamento de Bioestatística, Instituto de Biociências, \\ Universidade Estadual Paulista, Botucatu, SP, Brasil
}

\section{Correspondence \\ M.P. Okoshi \\ Departamento de Clínica Médica \\ Faculdade de Medicina de Botucatu, UNESP \\ 18618-000 Botucatu, SP \\ Brasil \\ Fax: 55 (014) 822-2238}

The present address of P.J.F. Tucci is Departamento de Fisiologia, Universidade Federal de São Paulo, São Paulo, SP, Brasil.

Research supported by FAPESP (No. 91/3666-9).

Received November 4, 1996 Accepted September 16, 1997

\begin{abstract}
The influence of afterload on the rate of force generation by the myocardium was investigated using two types of preparations: the in situ dog heart (dP/dt) and isolated papillary muscle of rats (dT/dt). Thirteen anesthetized, mechanically ventilated and thoracotomized dogs were submitted to pharmacological autonomic blockade $(3.0 \mathrm{mg} /$ $\mathrm{kg}$ oxprenolol plus $0.5 \mathrm{mg} / \mathrm{kg}$ atropine). A reservoir connected to the left atrium permitted the control of left ventricular end-diastolic pressure (LVEDP). A mechanical constriction of the descending thoracic aorta allowed to increase the systolic pressure in two steps of $20 \mathrm{mmHg}$ (conditions $\mathrm{H}_{1}$ and $\mathrm{H}_{2}$ ) above control values (condition C). After arterial pressure elevations (systolic pressure $\mathrm{C}: 119 \pm 8.1 ; \mathrm{H}_{1}$ : $\left.142 \pm 7.9 ; \mathrm{H}_{2}: 166 \pm 7.7 \mathrm{mmHg} ; \mathrm{P}<0.01\right)$, there were no significant differences in heart rate $\left(\mathrm{C}: 125 \pm 13.9 ; \mathrm{H}_{1}: 125 \pm 13.5 ; \mathrm{H}_{2}: 123 \pm 14.1\right.$ bpm; P>0.05) or LVEDP (C: $6.2 \pm 2.48 ; \mathrm{H}_{1}: 6.3 \pm 2.43 ; \mathrm{H}_{2}: 6.1 \pm 2.51$ $\mathrm{mmHg} ; \mathrm{P}>0.05)$. The values of $\mathrm{dP} / \mathrm{dt}$ did not change after each elevation of arterial pressure (C: $3,068 \pm 1,057 ; \mathrm{H}_{1}: 3,112 \pm 996 ; \mathrm{H}_{2}$ : $3,086 \pm 980 \mathrm{mmHg} / \mathrm{s} ; \mathrm{P}>0.05)$. In isolated rat papillary muscle, an afterload corresponding to $50 \%$ and $75 \%$ of the maximal developed tension did not alter the values of the maximum rate of tension development (100\%: $78 \pm 13$; 75\%: $80 \pm 13$; 50\%: $79 \pm 11 \mathrm{~g} \mathrm{~mm}^{-2}$ $\left.\mathrm{s}^{-1}, \mathrm{P}>0.05\right)$. The results show that the rise in afterload per se does not cause changes in $\mathrm{dP} / \mathrm{dt}$ or $\mathrm{dT} / \mathrm{dt}$.
\end{abstract}

Key words

- Ventricular function

- Afterload

- $\mathrm{dP} / \mathrm{dt}$

- $\mathrm{dT} / \mathrm{dt}$

- Papillary muscle

- Isometric contractions

\section{Introduction}

The rate of left ventricular pressure development $(\mathrm{dP} / \mathrm{dt})$ has been widely used to evaluate myocardium contractility. Several studies (1-7) have suggested that $\mathrm{dP} / \mathrm{dt}$ values depend on physiological factors altering cardiac performance other than inotropism, such as heart rate (HR) and preload.

Concerning the influence of afterload on $\mathrm{dP} / \mathrm{dt}$, the available data (1-3,5,7-15) point to a very controversial situation. From a linear point of view, it would be natural to expect that the maximal $\mathrm{dP} / \mathrm{dt}$ value is not changed by the aortic diastolic pressure rise since its maximum positive value occurs before aor- 
tic valve opening takes place $(6,8,16)$. However, the results of the studies which evaluated the influence of afterload on $\mathrm{dP} / \mathrm{dt}$ are discrepant. Some investigators $(3,8-12)$ have reported that the rise in arterial pressure (AP) did not interfere with the $\mathrm{dP} / \mathrm{dt}$ values, whereas others $(1,2,5,7,13-15)$ reported a direct relationship between AP rise and $\mathrm{dP} /$ dt. The divergent results may be due to different influences of other variables which do not present the same behavior in these different studies, such as preload and coronary perfusion pressure or coronary flow.

The purpose of the present study was to re-examine the effects of afterload variations on the rate of force generation by the myocardium, trying to eliminate the preload influence. We studied the effect of afterload elevations on $\mathrm{dP} / \mathrm{dt}$ in the in situ dog heart and on dT/dt in isolated papillary muscle preparations. In thein situ dog heart preparation, the AP was elevated while the left ventricular end-diastolic pressure (LVEDP) was kept constant. In the isolated muscle preparation a constant preload and myocardium nutrition allowed by diffusion eliminated the Frank-Starling mechanism and also the influences of coronary perfusion on $\mathrm{dT} / \mathrm{dt}$.

\section{Material and Methods}

\section{In situ dog heart}

Thirteen mongrel dogs weighing 15 to 35 $\mathrm{kg}$, anesthetized with $2 \mathrm{mg} / \mathrm{kg}$ meperidine, im, and $60 \mathrm{mg} / \mathrm{kg}$ chloralose and $600 \mathrm{mg} / \mathrm{kg}$ urethan, $i v$, and mechanically ventilated were submitted to midline thoracotomy. The thoracic aorta was repaired with cardiac tape below the emergence of the left subclavian artery. The pericardium was opened from the apex of the heart to the emergence of the pulmonary artery and used to support the heart as a pericardial cradle permitting a suitable exposure of the left atrium (LA) appendage. A catheter (4 cm long, $1.4 \mathrm{~mm}$ internal diameter) was introduced into the left ventricular cavity through the apex of the heart and the tip of another catheter $(100 \mathrm{~cm}$ long, $1.8 \mathrm{~mm}$ internal diameter) was placed in the ascending aorta from the left femoral artery and the distal extremities of both catheters were connected to pressure transducers (Statham P23-ID). Left ventricular pressure, $\mathrm{dP} / \mathrm{dt}$ and aortic pressure were obtained with a model 1205 pressure amplifier connected to an Electronics for Medicine VR-12 physiologic recorder. The left ventricular pressure was amplified as low and high gain records in order to analyze systolic and diastolic pressures. The $\mathrm{dP} / \mathrm{dt}$ ratio was obtained utilizing the differentiating circuit of the pressure amplifier (time constant: $0.1 \mathrm{~s}$; linear response until $200 \mathrm{~Hz}$ ). These variables and a bipolar lead of the electrocardiogram were continuously monitored.

The intravenous administration of 0.5 $\mathrm{mg} / \mathrm{kg}$ atropine and $3.0 \mathrm{mg} / \mathrm{kg}$ oxprenolol blocked parasympathetic and $B$-adrenergic activities. The $\beta$-adrenergic blockade obtained with oxprenolol was also sufficient to abolish the inotropic and chronotropic effects of isoproterenol $(1 \mu \mathrm{g} / \mathrm{kg}, i v)$.

The LVEDP was maintained constant during the rise in AP by using a circuit attached to the LA. The circuit included a reservoir with a limiting level system draining the blood of the LA appendage to another reservoir and a roller pump which pumps the blood to the jugular veins of the animal. When the ventricular filling pressure began to rise, the level of the liquid in the reservoir rose, allowing the blood to drain from the limiting level system to the second reservoir, from which it was then pumped to the dog jugular veins. Thus, the left ventricular filling pressure was kept at the initial value throughout the experiment.

After a 15-min stabilization period, the height of the reservoir was fixed to maintain the basal LVEDP level constant. When the preparation was stable, the variables were recorded under control (C) conditions after 
$10 \mathrm{~s}$ of expiratory apnea.

By means of the cardiac tape, the aorta was constricted until the systolic pressure was increased by approximately $20 \mathrm{mmHg}$ above control levels and arterial hypertension was sustained for $10 \mathrm{~min}$ in order to obtain the hypertension 1 condition $\left(\mathrm{H}_{1}\right)$. At the end of this period, the variables were recorded. The aortic constriction was released and the preparation was allowed to stabilize for $10 \mathrm{~min}$. Thereafter, these procedures were repeated to increase arterial pressure by approximately $40 \mathrm{mmHg}$ above control conditions and, after $10 \mathrm{~min}$, the variables were again recorded as hypertension 2 condition $\left(\mathrm{H}_{2}\right)$. The limiting system did not allow variations in the ventricular filling pressure during AP changes.

The following variables were analyzed: HR, left ventricular systolic pressure (LVSP), LVEDP, diastolic aortic pressure (DAP) and $\mathrm{dP} / \mathrm{dt}$.

\section{Isolated papillary muscle}

Ten male Wistar rats weighing 204 to $232 \mathrm{~g}$ were killed by decapitation. The hearts were quickly removed and placed in oxygenated Krebs-Henseleit solution at $28^{\circ} \mathrm{C}$. Trabecular carneae or papillary muscles were dissected from the left ventricle, mounted between two spring clips, and placed vertically in a chamber containing KrebsHenseleit solution at $28^{\circ} \mathrm{C}$ and gassed with $95 \% \mathrm{O}_{2}$ and $5 \% \mathrm{CO}_{2}$. The composition of the Krebs-Henseleit solution was as follows: $118.5 \mathrm{mM} \mathrm{NaCl}, 4.69 \mathrm{mM} \mathrm{KCl}, 2.52 \mathrm{mM}$ $\mathrm{CaCl}_{2}, 1.16 \mathrm{mM} \mathrm{MgSO}_{4}, 1.18 \mathrm{mM} \mathrm{KH}_{2} \mathrm{PO}_{4}$, $5.50 \mathrm{mM}$ glucose, and $25.88 \mathrm{mM} \mathrm{NaHCO}_{3}$. The lower spring clip was attached to a Kyowa model 120T-20B force transducer by a thin steel wire $(1 / 15,000$ inch), which passed through a mercury seal at the bottom of the chamber. The upper spring clip was connected by a thin steel wire to a rigid lever arm above which a micrometer stop was mounted for the adjustment of muscle length.
Preparations were stimulated 12 times/min with 5-ms square wave pulses through parallel platinum electrodes, at voltages $10 \%$ higher than the minimum required to produce a maximal mechanical response.

After a 60-min period during which the preparations were allowed to shorten while carrying light loads, muscles were loaded to contract isometrically and stretched to the apex of their length-tension curves $\left(\mathrm{L}_{\max }\right)$.

After a 5-min period during which preparations performed afterloaded isotonic contractions, muscles were again placed under isometric conditions, and the apex of the length-tension curve $\left(\mathrm{L}_{\max }\right)$ was again carefully determined. A 15-min period of stable isometric contraction was imposed prior to the experimental period and one isometric contraction was then recorded. Thereafter, the muscle was allowed to perform afterloaded isotonic contraction in which the developed tension was constant during muscle shortening. The level of developed tension was determined so that the active tension could reach $75 \%$ and, in the next step, $50 \%$ of the developed tension obtained in the isometric contraction. Resting tension was not changed, since the muscle was maintained at $\mathrm{L}_{\max }$ during the afterload variations. Under the present afterload conditions all the contractions were recorded after muscle stabilization.

The following parameters of the isometric contractions were measured: developed tension (DT, $\mathrm{g} / \mathrm{mm}^{2}$ ), resting tension (RT, g/ $\mathrm{mm}^{2}$ ), time to peak tension (TPT, ms) and maximum rate of tension development (dT/ $\mathrm{dt}, \mathrm{g} \mathrm{mm}^{-2} \mathrm{~s}^{-1}$ ). For afterloaded contractions, DT, RT and dT/dt were assessed.

At the end of each experiment, the muscle length at $\mathrm{L}_{\max }$ was measured and the muscle between the two clips was blotted dry and weighed. Cross-sectional areas were calculated from the muscle weight and length by assuming cylindrical uniformity and a specific gravity of 1.0. All force data were normalized for the muscle cross-sectional area. 


\section{Statistical analysis}

Data are reported as mean $\pm \mathrm{SD}$. The comparisons of HR, LVSP, DAP, LVEDP and $\mathrm{dP} / \mathrm{dt}$ values obtained under the $\mathrm{C}, \mathrm{H}_{1}$ and $\mathrm{H}_{2}$ conditions, as well as $\mathrm{dT} / \mathrm{dt}$ values verified in the different afterloads, were made by repeated measurement analysis (multivariate analysis - mean profile). Differences were considered to be significant when $\mathrm{P}<0.05$ (17).

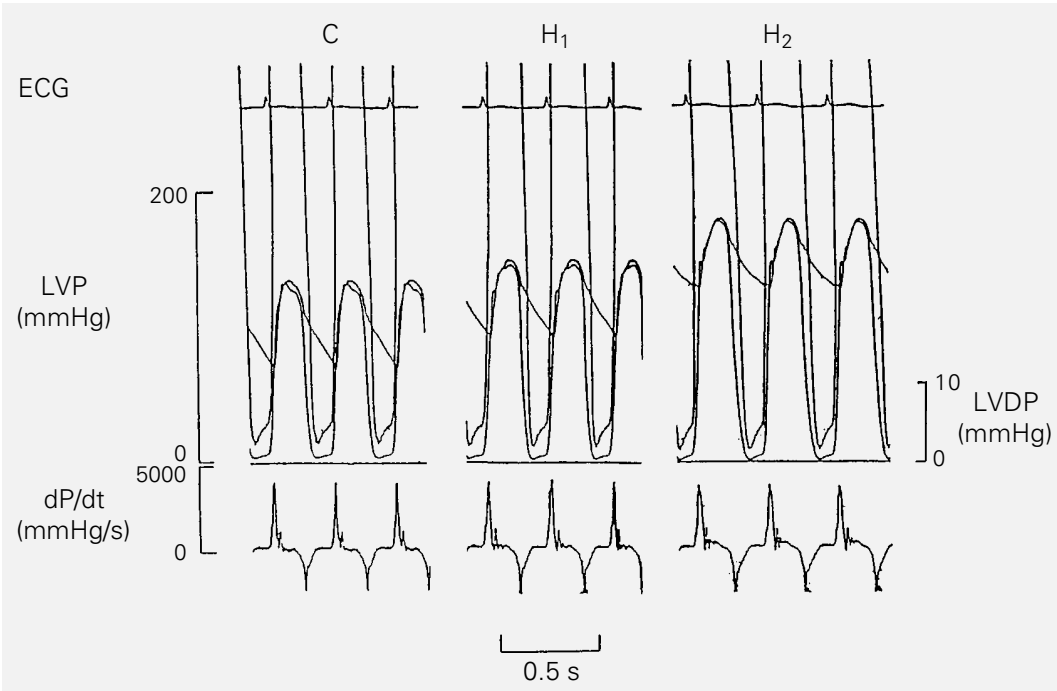

Figure 1 - Record from one in situ dog heart experiment. Effect of sustained elevation (10 $\mathrm{min}$ ) of aortic pressure on $\mathrm{dP} / \mathrm{dt}$ with constant left ventricular end-diastolic pressure. $\mathrm{C}=$ Control, $\mathrm{H}_{1}=$ hypertension $1, \mathrm{H}_{2}=$ hypertension $2, \mathrm{ECG}=$ electrocardiogram, LVP = left ventricular pressure, LVDP (left ventricular diastolic pressure) = LVP at higher gain to show diastolic part (systole off scale), $\mathrm{dP} / \mathrm{dt}=$ rate of rise of the left ventricular pressure.

Table 1 - Effects of arterial pressure increases on cardiac parameters of dogs.

Data are reported as mean $\pm S D(N=13) . H R=$ Heart rate; $L V S P=$ left ventricular systolic pressure; $\mathrm{DAP}=$ diastolic aortic pressure; $L$ LEDP $=$ left ventricular enddiastolic pressure; $\mathrm{dP} / \mathrm{dt}=$ rate of rise of the left ventricular pressure; $\mathrm{C}=$ control; $\mathrm{H}_{1}=$ hypertension 1 condition; $\mathrm{H}_{2}=$ hypertension 2 condition. ${ }^{*} \mathrm{P}<0.01$ vs $\mathrm{C} ;{ }^{+} \mathrm{P}<0.01$ vs $\mathrm{H}_{1}$ (repeated measurement analysis).

\begin{tabular}{lccccc}
\hline & $\mathrm{HR}(\mathrm{bpm})$ & $\operatorname{LVSP}(\mathrm{mmHg})$ & $\mathrm{DAP}(\mathrm{mmHg})$ & $\operatorname{LVEDP}(\mathrm{mmHg})$ & $\mathrm{dP} / \mathrm{dt}(\mathrm{mmHg} / \mathrm{s})$ \\
\hline $\mathrm{C}$ & $125 \pm 13.9$ & $119 \pm 8.1$ & $89 \pm 11.6$ & $6.2 \pm 2.48$ & $3,068 \pm 1,057$ \\
$\mathrm{H}_{1}$ & $125 \pm 13.5$ & $142 \pm 7.9^{*}$ & $99 \pm 9.5^{*}$ & $6.3 \pm 2.43$ & $3,112 \pm 996$ \\
$\mathrm{H}_{2}$ & $123 \pm 14.1$ & $166 \pm 7.7^{*+}$ & $120 \pm 11.8^{*+}$ & $6.1 \pm 2.51$ & $3,086 \pm 980$
\end{tabular}

\section{Results}

\section{In situ dog heart preparation}

Table 1 shows the data obtained under the $\mathrm{C}, \mathrm{H}_{1}$ and $\mathrm{H}_{2}$ conditions. Statistical analysis revealed that LVSP $\left(\mathrm{C}: 119 \pm 8.1 ; \mathrm{H}_{1}\right.$ : $142 \pm 7.9 ; \mathrm{H}_{2}: 166 \pm 7.7 \mathrm{mmHg}$ ) and DAP $\left(\mathrm{C}: 89 \pm 11.6 ; \mathrm{H}_{1}: 99 \pm 9.5 ; \mathrm{H}_{2}: 120 \pm 11.8\right.$ $\mathrm{mmHg})$ were significantly different $(\mathrm{C}<$ $\left.\mathrm{H}_{1}<\mathrm{H}_{2}, \mathrm{P}<0.01\right)$. There was no significant variation in $\mathrm{HR}\left(\mathrm{C}: 125 \pm 13.9 ; \mathrm{H}_{1}: 125 \pm\right.$ $\left.13.5 ; \mathrm{H}_{2}: 123 \pm 14.1 \mathrm{bpm}\right), \operatorname{LVEDP}(\mathrm{C}: 6.2 \pm$ $2.48 ; \mathrm{H}_{1}: 6.3 \pm 2.43 ; \mathrm{H}_{2}: 6.1 \pm 2.51 \mathrm{mmHg}$ ) or $\mathrm{dP} / \mathrm{dt}\left(\mathrm{C}: 3,068 \pm 1,057 ; \mathrm{H}_{1}: 3,112 \pm 996\right.$; $\mathrm{H}_{2}: 3,086 \pm 980 \mathrm{mmHg} / \mathrm{s}$ ) during AP changes. Figure 1 shows the records obtained in one of the experiments.

\section{Isolated papillary muscle}

Table 2 shows the basal data obtained during the isometric contraction of the muscles at $\mathrm{L}_{\max }$. Table 3 shows the values of peak dT/dt under the different afterloaded conditions analyzed in the isolated muscle strips. Peak dT/dt was obtained at contractions with developed tension levels corresponding to $100 \%\left(\mathrm{dT} / \mathrm{dt}: 78 \pm 13 \mathrm{~g} \mathrm{~mm}^{-2} \mathrm{~s}^{-1}\right.$ ), $75 \%$ (dT/dt: $80 \pm 13 \mathrm{~g} \mathrm{~mm}^{-2} \mathrm{~s}^{-1}$ ), and 50\% (dT/dt: $\left.79 \pm 11 \mathrm{~g} \mathrm{~mm}^{-2} \mathrm{~s}^{-1}\right)$ of the developed tension verified in isometric contraction. No significant difference $(\mathrm{P}>0.05)$ was found in peak $\mathrm{dT} / \mathrm{dt}$ values at the three different afterloads.

\section{Discussion}

Our results obtained with the isolated papillary muscle preparations support the view that the amount of developed force did not interfere with the intensity of the activation process. At present, two known factors are suggested as potentially affecting the rate of myocardial force generation when afterload changes: the Anrep effect (15,18-20) and the shortening deactivation (21-23). Until 
recently, there was no consistent evidence that the Anrep effect could be demonstrated in muscle strips. A few years ago, Nichols et al. (20) convincingly demonstrated the occurrence of the Anrep effect in muscle strips specially instrumented in order to obtain "physiological" contraction. In isolated muscles studied in isometric and afterloaded contractions as those utilized by us, it was not possible for these authors to identify the influence of the Anrep effect on the contraction. On the other hand, contraction deactivation due to shortening has been described under various types of experimental conditions (21-24). It seems valid to assume that shortening deactivation did not occur in our study. Indeed, if shortening deactivation had occurred, peak dT/dt should have proportionally decreased in contractions studied under afterloaded conditions, i.e., $75 \%$ and $50 \%$ of isometric contractions. Recently, Konishi et al. (7) described a direct correlation between afterload and peak dT/dt in contractions analyzed in a range of force that was $14 \%$ to $70 \%$ of isometric contractions. It seems that the wide range of developed force could facilitate the occurrence of shortening deactivation. Moreover, such a small afterload should prevent the occurrence of the maximal $\mathrm{dT} / \mathrm{dt}$ value since force development was interrupted early $(8,9)$.

In the in situ canine heart preparation, the rise in AP also did not promote any increase in the $\mathrm{dP} / \mathrm{dt}$ values. Since we maintained the left ventricular filling pressure constant during the rise in aortic pressure, we prevented the participation of the Frank-Starling mechanism in our experiments and eliminated a spurious factor of interference with the results that others have not provided $(2,13)$.

According to present knowledge, other factors that may alter the $\mathrm{dP} / \mathrm{dt}$ values after increasing AP are shortening deactivation (21-24), the Anrep effect $(15,18,19)$ and variations in coronary flow (25) or coronary perfusion pressure (26). Previous studies from our laboratory have shown that large increases of developed force (27) and coronary perfusion (28) do affect left ventricular performance in the intact canine left ventricle. The influence of afterload is thought to be linked to the Anrep effect and, typically, occurs as a cyclic and transitory oscillation of cardiac performance (29). There is an initial impairment of contraction followed by improvement of ventricular performance until complete recovery. A reduction of the subendocardial coronary flow followed by restoration of myocardial perfusion seems to be implicated when the Anrep effect occurs in the intact heart $(18,19)$. Complete cardiac influence of the Anrep effect is limited to a few minutes, and is certainly not present at the end of $10 \mathrm{~min}$. It has been described that, in addition to myocardial ischemia, coronary perfusion pressure can affect cardiac mechanics interfering with intracellular calcium concentration $(30,31)$ and sarcomere resting length $(26,32)$. Abel and Reis (25) described an enhancement of cardiac performance following the increase of coronary

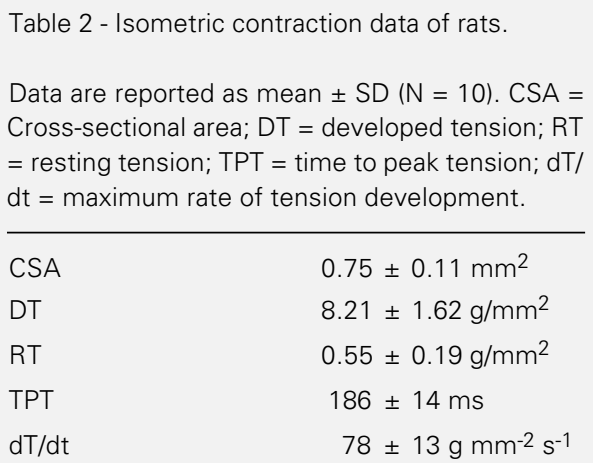

Table 3 - Effect of afterload changes on dT/dt.

Data are reported as mean $\pm S D(N=10)$. $D T=$ Developed tension; $d T / d t=$ maximum rate of tension development ( $P>0.05$ for $\mathrm{dT} / \mathrm{dt}$; repeated measurement analysis)

\begin{tabular}{lccr}
\hline & \multicolumn{4}{c}{ Afterload (\% of DT in isometric contraction) } \\
\cline { 2 - 4 } & $50 \%$ & $75 \%$ & $100 \%$ \\
\hline DT $\left(\mathrm{g} / \mathrm{mm}^{2}\right)$ & $4.0 \pm 0.88$ & $6.11 \pm 2.5$ & $8.21 \pm 1.62$ \\
$\mathrm{dT} / \mathrm{dt}\left(\mathrm{g} \mathrm{mm}^{-2} \mathrm{~s}^{-1}\right)$ & $79 \pm 11$ & $80 \pm 13$ & $78 \pm 13$
\end{tabular}


flow without changes in perfusion pressure. The mechanisms underlying this effect of flow on cardiac mechanics are unknown. Since in the in situ dog heart preparations arterial pressure has always been manipulated in order to increase AP, the cumulative effects of shortening deactivation, Anrep effect and coronary perfusion should enhance ventricular performance. In spite of the possible concurrence of these factors in heightening contraction, an elevation of peak $\mathrm{dP} / \mathrm{dt}$ was not verified. It seems pertinent to conclude that, in the in situ dog heart, variations in arterial pressure within wide physiological ranges do not affect per se the maximal values of $\mathrm{dP} / \mathrm{dt}$. A particular exception is represented by those situations in which there is an expressive reduction in diastolic arterial pressure. Under such conditions, the values of $\mathrm{dP} / \mathrm{dt}$ would not represent the maximum contractile performance of cardiac muscle, since premature shortening prevents the actual peak of $\mathrm{dP} / \mathrm{dt}$. Moreover, coronary flow should be impaired when diastolic arte- rial pressure is under the values of autoregulatory mechanism. This seems to be a fitting interpretation for the diverging results recently described by Konishi et al. (7) studying working rat heart preparations. These investigators utilized peak systolic pressures ranging from 66 to $97 \mathrm{mmHg}$ and found that the rise in aortic pressure was accompanied by elevations of peak $\mathrm{dP} / \mathrm{dt}$. This seems to be an inconvenient pressure range to be studied.

In conclusion, the present results suggest that the increase in afterload does not cause changes in the $\mathrm{dP} / \mathrm{dt}$ or $\mathrm{dT} / \mathrm{dt}$ values.

\section{Acknowledgments}

The authors thank José Carlos Georgette and Vitor Marcos de Souza for technical assistance and Alvaro Oscar Campana, Luiz Shiguero Matsubara, Sergio Alberto Rupp de Paiva and Mario Augusto Dallaqua for help with manuscript preparation.

\section{References}

1. Wallace AG, Skinner NS \& Mitchel JH (1963). Hemodynamic determinants of the maximal rate of rise of left ventricular pressure. American Journal of Physiology, 205: 30-36.

2. Barnes GE, Bishop VS, Horwitz LD \& Kaspar RL (1973). The maximum derivatives of left ventricular pressure and transverse internal diameter as indices of the inotropic state of the left ventricle in conscious dogs. Journal of Physiology, 235: 571-590.

3. Mahler F, Ross Jr J, O'Rourke RA \& Covell JW (1975). Effects of changes in preload, afterload and inotropic state on ejection and isovolumic phase measures of contractility in the conscious dog. American Journal of Cardiology, 35: 626-634.

4. Schmidt HD \& Hoppe $H$ (1978). Preload dependence of $\mathrm{dP} / \mathrm{dt}$ max, Vce max and calculated $V$ max compared to the inotropic sensitivity of these indices of cardiac contractility. Basic Research in Cardiology, 73: 380-393.
5. Kass DA, Maughan WL, Guo ZM, Kono A, Sunagawa K \& Sagawa K (1987). Comparative influence of load versus inotropic states on indexes of ventricular contractility: experimental and theoretical analysis based on pressure-volume relationships. Circulation, 76: 1422-1436.

6. Little WC, Cheng CP, Mumma M, Igarashi $Y$, Vinten-Johansen J \& Johnston WE (1989). Comparison of measures of left ventricular contractile performance derived from pressure-volume loops in conscious dogs. Circulation, 80: 1378-1387.

7. Konishi T, Nakamura Y, Kato I \& Kawai C (1992). Dependence of peak dP/dt and mean ejection rate on load and effect of inotropic agents on the relationship between peak $\mathrm{dP} / \mathrm{dt}$ and left ventricular developed pressure - assessed in the isolated working rat heart and cardiac muscles. International Journal of Cardiology, 35: 333-341.
8. Quinones MA, Gaasch WH \& Alexander JK (1976). Influence of acute changes in preload, afterload, contractile state and heart rate on ejection and isovolumic indices of myocardial contractility in man. Circulation, 53: 293-302.

9. Siegel JH, Sonnenblick EH, Judge RD \& Wilson WS (1964). The quantification of myocardial contractility in dog and man. Cardiologia, 45: 189-220.

10. Bugge-Asperheim B \& Kiil F (1973) Preload, contractility, and afterload as determinants of stroke volume during elevation of aortic blood pressure in dogs. Cardiovascular Research, 7: 528-541.

11. Elzinga G, Noble MIM \& Stubbs J (1977) The effect of an increase in aortic pressure upon the inotropic state of cat and dog left ventricles. Journal of Physiology, 273: 597-615

12. Starling MR, Montgomery DG \& Walsh RA (1989). Load dependence of the single beat maximal pressure (stress)/volume ratios in humans. Journal of the American College of Cardiology, 14: 345-353. 
13. Clancy RL, Graham Jr TP, Ross Jr J, Sonnenblick EH \& Braunwald E (1968). Influence of aortic pressure-induced homeometric autoregulation on myocardial performance. American Journal of Physiology, 214: 1186-1192.

14. Henning RJ \& Levy MN (1991). Effects of autonomic nerve stimulation asynchrony, and load on $\mathrm{dP} / \mathrm{dt}$ max and on $\mathrm{dP} / \mathrm{dt}$ min. American Journal of Physiology, 260: H1290-H1298.

15. Schipke JD, Stocks I, Sunderdiek U \& Arnold G (1993). Effect of changes in aortic pressure and in coronary arterial pressure on left ventricular geometry and function. Anrep vs. gardenhose effect. Basic Research in Cardiology, 88: 621637.

16. Little WC (1985). The left ventricular dP/ dtmax - end-diastolic volume relation in closed-chest dogs. Circulation Research, 56: 808-815

17. Morrison DF (1976). Multivariate Statistical Methods. 2nd edn. McGraw-Hill Kogabusha Ltd., Tokyo.

18. Monroe RG, Gamble WJ, LaFarge CG, Kumar AE, Stark J, Sanders GL, Phornphutkul C \& Davis M (1972). The Anrep effect reconsidered. Journal of Clinical Investigation, 51: 2573-2583

19. Walston A, Rembert JC, Fedor JM \& Greenfield Jr JC (1978). Regional myocardial blood flow after sudden aortic constriction in awake dogs. Circulation Research, 42: 419-425.
20. Nichols CG, Hanck DA \& Jewell BR (1988). The Anrep effect: an intrinsic myocardial mechanism. Canadian Journal of Physiology and Pharmacology, 66: 924929.

21. Leach JK, Brady AJ, Skipper BJ \& Millis DL (1980). Effects of active shortening on tension development of rabbit papillary muscle. American Journal of Physiology, 238: $\mathrm{H} 8-\mathrm{H} 13$

22. Housmans PR, Lee NKM \& Blinks JR (1983). Active shortening retards the decline of the intracellular calcium transient in mammalian heart muscle. Science, 221: 159-161.

23. Hunter WC (1989). End-systolic pressure as a balance between opposing effects of ejection. Circulation Research, 64: 265275.

24. Suga H, Saeki Y \& Sagawa K (1977). Endsystolic force-length relationship of nonexcised canine papillary muscle. American Journal of Physiology, 233: H711-H717.

25. Abel RM \& Reis RL (1970). Effect of coronary blood flow and perfusion pressure on left ventricular contractility in dogs. Circulation Research, 27: 961-971.

26. Arnold G, Kosche F, Miessner E, Neitzert A \& Lochner W (1968). The importance of the perfusion pressure in the coronary arteries for the contractility and the oxygen consumption of the heart. Pflügers Archives, 299: 339-356.
27. Tucci PJF, Bregagnollo EA, Spadaro J, Cicogna AC \& Ribeiro MCL (1984). Length dependence of activation studied in the isovolumic blood-perfused dog heart. Circulation Research, 55: 59-66.

28. Tucci PJF, Spadaro J, Cicogna AC \& Bregagnollo EA (1980). Coronary perfusion pressure as a determinant of ventricular performance. Experientia, 36: 974975.

29. Sarnoff SJ \& Mitchel JH (1961). The regulation of the performance of the heart. American Journal of Medicine, 30: 747765.

30. Haneda $T$, Watson PA \& Morgan HE (1989). Elevated aortic pressure, calcium uptake, and protein synthesis in rat heart. Journal of Molecular and Cellular Cardiology, 21 (Suppl 1): 131-138.

31. Kitakaze M \& Marban E (1989). Cellular mechanism of the modulation of contractile function by coronary perfusion pressure in ferret heart. Journal of Physiology, 414: 455-472.

32. Miller WP, Shimamoto N, Nellis $\mathrm{SH} \&$ Liedtke AJ (1987). Coronary hyperperfusion and myocardial metabolism in isolated and intact hearts. American Journal of Physiology, 253: 1271-1278. 